\title{
CAPÍTULO 02: DESENVOLVIMENTO, CARACTERIZAÇÃO E ACEITABILIDADE DE BROWNIE DE CHOCOLATE ELABORADO COM FARINHA DE INHAME (Dioscorea sp.) POR SECAGEM CONVECTIVA
}

\section{CHAPTER 02: DEVELOPMENT, CHARACTERIZATION AND ACCEPTABILITY OF CHOCOLATE BROWNIE MADE WITH INHAME FLOUR (Dioscorea sp.) BY CONVECTIVE DRYING}

\begin{abstract}
Joyce Maria Santino de Oliveira ${ }^{1}$; Luzia Marcia de Melo Silva ${ }^{2}$; Neide Aparecida Ferreira Machado $^{3}$; Julio Augusto Enders de Albuquerque ${ }^{4}$; Francinalva Cordeiro de Sousa ${ }^{5}$
\end{abstract}

\begin{abstract}
Resumo
Este trabalho teve como objetivo estudar o processo de secagem do inhame em estufa, a elaboração de uma farinha para o processamento de brownie e analisar a aceitabilidade do produto. $\mathrm{O}$ inhame in natura foi caracterizado físico-quimicamente e passou pelo processo de secagem convectiva em estufa com circulação forçada de ar em três temperaturas $(50,60$ e $70^{\circ} \mathrm{C}$ ). As farinhas obtidas foram caracterizadas quanto aos parâmetros físico-químicos, tecnológicos e microbiológicos. Foram desenvolvidas cinco formulações de brownies, com diferentes concentrações da farinha de inhame, e submetidos as análises físico-químicas, microbiológicas e sensoriais. Os dados obtidos das caracterizações físico-químicas do inhame in natura, das farinhas de inhame e dos brownies foram submetidos à análise de variância (ANOVA) e as médias foram comparadas pelo teste de Tukey $(\mathrm{p} \leq 0,05)$. Constatou-se que os produtos elaborados estão dentro dos padrões exigidos pela legislação e os resultados da análise sensorial foram satisfatórios para o brownie elaborado com $100 \%$ de farinha de inhame.
\end{abstract}

Palavras-Chaves: Glúten, Massas alimentícias, Processamento de alimentos, Análises físicoquímicas, Análises microbiológicas.

\begin{abstract}
This work aimed to study the drying process of yam in the greenhouse, the preparation of a flour for brownie processing and to analyze the acceptability of the product. The fresh yam was characterized physically and chemically and went through the process of convective drying in an oven with forced air circulation at three temperatures $\left(50,60\right.$ and $\left.70^{\circ} \mathrm{C}\right)$. The flours obtained were characterized in terms of physical-chemical, technological and microbiological parameters. Five brownie formulations were developed, with different concentrations of yam flour, and subjected to physical-chemical, microbiological and sensory analyzes. The data obtained from the physical-chemical characterizations of fresh yams, yam flours and brownies were subjected to analysis of variance (ANOVA) and the means were compared using the Tukey test $(\mathrm{p} \leq 0.05)$. It was found that the products produced are within the standards required by law and the results of the sensory analysis were satisfactory for the brownie made with $100 \%$ yam flour.
\end{abstract}

Keywords: Gluten, Pasta, Food processing, Physical-chemical analysis, Microbiological analysis.

\footnotetext{
${ }^{1}$ Tecnologia de Alimentos, Instituto Federal de Alagoas - IFAL, mariajoyce1.jm@ gmail.com

${ }^{2}$ Tecnologia de Alimentos, Instituto Federal de Alagoas - IFAL, luzia.silva@ifal.edu.br

${ }^{3}$ Tecnologia de Laticínios, Instituto Federal de Alagoas - IFAL, neideferr@gmail.com

${ }^{4}$ Administração, Universidade Federal de Alagoas - UFAL, julioenders@ outlook.com

${ }^{5}$ Tecnologia de Alimentos, Instituto Federal de Pernambuco - IFPE, francinalvacordeiro@barreiros.ifpe.edu.br
} 


\section{Introdução}

A boa alimentação se relaciona ao bem-estar do indivíduo e a satisfação alimentar está inteiramente ligada à qualidade do produto que está sendo ingerido, de acordo com seu aspecto nutricional, sensorial e microbiológico. Cerca de $57 \%$ da população brasileira preferem incluir em suas compras alimentos funcionais, como grãos, raízes e tubérculos, e sua utilização, na maioria das vezes, é realizada como substituição de outros alimentos como garantia de um melhor funcionamento do organismo, manutenção da saúde e na prevenção de alguma intolerância ou alergia alimentar (NIELSEN, 2016).

Ainda, de acordo com a pesquisa realizada pela NIELSEN (2016) 48\% dos brasileiros disseram ter algum tipo de alergia ou intolerância alimentar a um ou mais gêneros alimentícios. Dentre os alimentos que ocasionam as intolerâncias alimentares, destacam-se o trigo, cevada, centeio, aveia etc., que contém glúten e recebe nomes diferentes para cada cereal (ARAÚJO, 2010). O glúten presente no trigo é caracterizado por uma proteína amorfa composta pela mistura de cadeias proteicas longas de gliadina e glutenina, na cevada é a hordeína, no centeio é a secalina e na aveia é a avenina (RODRIGUES et al., 2017, p. 187). Os portadores da Doença Celíaca (DC) não devem consumir produtos alimentícios que contenha glúten em sua composição, visto que, pequenas quantidades da proteína podem desencadear reações causadas pela doença como: diarreia crônica, vômitos, dor abdominal, anemia etc. (SILVA; FURLANETTO, 2010).

A ausência de tolerância ao glúten, identificada como DC, é caracterizada pela produção de anticorpos ao glúten, que agem no intestino delgado, atrofiando-o, em indivíduos predispostos geneticamente, ocasionando a má absorção de nutrientes, vitaminas, sais minerais e água, e o único tratamento para minimizar os efeitos colaterais é uma dieta isenta ao glúten (RODRIGUES et al., 2017, p. 187).

Grande parte dos produtos de amidonarias, que compreendem o setor de farinhas, panificação e massas alimentícias, têm como base de matéria prima a farinha do trigo, que, segundo a Companhia Nacional de Abastecimento (CONAB, 2017) é o cereal mais produzido no mundo. Entretanto, a produção de farinhas a partir de tubérculos, como o inhame (Dioscorea spp.), vem sendo pesquisada como alternativa para elaboração de produtos isentos ao glúten, destinados aos portadores da DC, por ser um alimento de fácil acesso, excelente qualidade nutritiva, energética e de preço acessível (OLIVEIRA et al., 2018; PESSOA et al., 2017).

O inhame (Dioscorea sp.) é uma planta monocotiledônea, herbácea, trepadeira, de clima tropical e subtropical, com grande importância socioeconômica no Nordeste (OLIVEIRA et al., 2018). Em Alagoas, estado em que este trabalho foi desenvolvido, estima-se que existam cerca 
de 2.290 hectares destinados ao cultivo do inhame (Dioscorea sp.), com produtividade média de 12 toneladas por hectare, representando a principal atividade econômica da agricultura familiar da região (LEÃO; CLEMENTINO; BARROS, 2017). O tubérculo é rico em proteína, potássio e cerca de $30 \%$ de sua composição é amido, fonte de energia, sendo parte dele o amido digerido lentamente, que é associado a um melhor controle de diabetes (CHEN et al., 2017; WALTER et al., 2005).

Apesar de suas características, o inhame (Dioscorea sp.) está entre os vegetais subutilizados (PESSOA et al., 2017). O tubérculo é produzido em pequena escala, geralmente, por pequenos agricultores familiares. Sua produção sazonal e problemas no armazenamento são fatores que dificultam seu uso (YASHIKI; TRIBOLI, 2018). Uma alternativa viável é a produção de farinhas a partir do inhame que facilitaria o armazenamento, teria maior disponibilidade de produto, maior vida de prateleira e seria a base para a produção de diversos subprodutos como pães, bolos, brownies etc.

Pelo seu valor nutricional, funcional e pela facilidade de acesso a esse tubérculo na região do Nordeste, o objetivo desta pesquisa foi estudar o processo de secagem do inhame em estufa e a elaboração de uma farinha para processamento de brownie de chocolate.

\section{Material e Métodos}

\section{Obtenção da matéria-prima}

O inhame (Dioscorea sp.) foi adquirido na feira livre local do município de Murici AL. Os tubérculos passaram pelo processo de higienização, que compreende as etapas de limpeza e sanitização, para minimizar a quantidade de microrganismos deterioradores e patogênicos (BRASIL, 2004). Posteriormente, o tubérculo foi descascado, com auxílio de uma faca de aço inoxidável, cortado em tiras de $1 \mathrm{~cm}$ e submetidos à secagem em estufa com circulação forçada de ar (Figura 1). As etapas desta pesquisa foram realizadas no Laboratório de Produtos de Origem Vegetal do Instituto Federal de Alagoas (IFAL) - Campus Murici, Laboratório de Microbiologia do IFAL - Campus Maceió e no Laboratório de Armazenamento e Processamento de Produtos Agrícolas, pertencente à Universidade Federal de Campina Grande (UFCG).

\section{Caracterização físico-química do inhame in natura}

$\mathrm{O}$ inhame in natura foi caracterizado, em triplicata, quanto aos parâmetros físicoquímicos: pH, acidez total titulável, sólidos solúveis totais, teor de água e sólidos totais conforme as Normas Analíticas do Instituto Adolfo Lutz (BRASIL, 2008). 


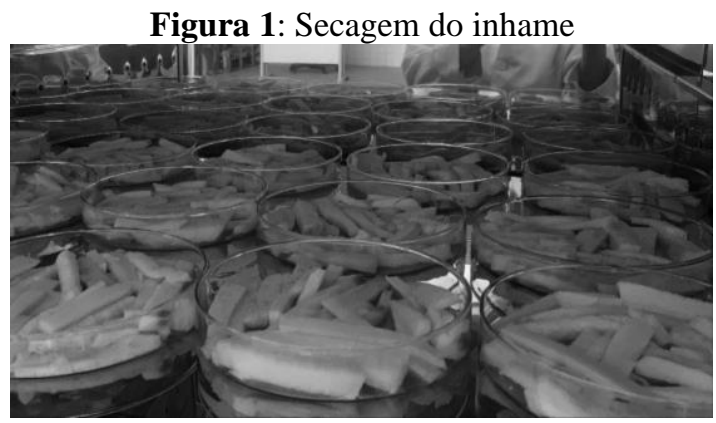

Fonte: Próprio autor

\section{Secagem}

Para a obtenção da farinha de inhame, foram realizados testes preliminares em estufa com circulação forçada de ar em diferentes temperaturas, 50, 60 e $70^{\circ} \mathrm{C}$, por aproximadamente 12 horas. A escolha da temperatura de secagem ideal para realizar os demais experimentos foi baseada na escolha de uma farinha mais fluida, partículas mais aglomeradas e menor teor de água. Verificou-se que a melhor condição de secagem foi a temperatura de $70^{\circ} \mathrm{C}$, que produziu uma farinha com todas as características desejáveis. Após o processo de secagem, a matériaprima desidratada foi acondicionada em dessecador para evitar trocas gasosas com o ambiente, até o momento da desintegração e posterior caracterização físico-química.

\section{Elaboração da farinha de inhame}

Após a secagem, o tubérculo foi desintegrado manualmente, com auxílio de um cadinho e pistilo, obtendo a farinha, sendo posteriormente peneirada, fracionada e acondicionada em embalagens plásticas (Figura 2).

Figura 2: Farinha do inhame

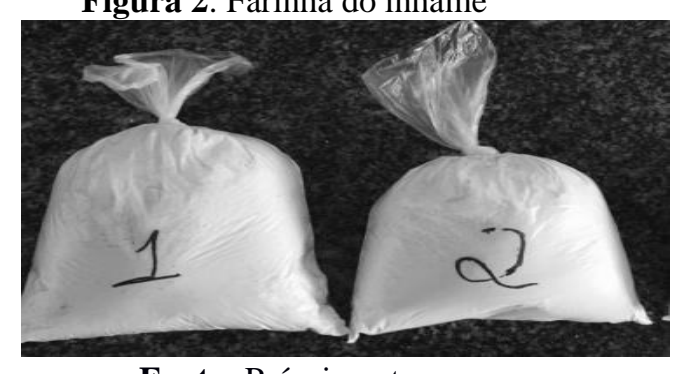

Fonte: Próprio autor

\section{Caracterização físico-química da farinha de inhame}

As farinhas produzidas nas diferentes temperaturas foram caracterizadas quanto aos parâmetros físico-químicos: sólidos solúveis totais, teor de água, sólidos totais, $\mathrm{pH}$, acidez total titulável, e atividade de água, conforme metodologia descrita por Brasil (2008). A amostra que apresentou teor de água favorável dentro dos padrões estabelecidos pela legislação foi escolhida 
para a elaboração dos brownies e caracterizada quanto aos parâmetros tecnológicos e microbiológicos.

\section{Análises tecnológicas da farinha}

Os parâmetros avaliados foram: densidade aparente (SOUZA et al., 2010); densidade compactada (GOULA; ADAMOPOULOS, 2004); fator de Hausner e índice de compressibilidade (YUSOF et al., 2012).

\section{Análises microbiológicas da farinha}

A farinha de inhame foi submetida à análise microbiológica quando aos parâmetros exigidos pela legislação vigente: Coliformes a $35^{\circ}$ e a $45^{\circ} \mathrm{C}$, bactérias aeróbias mesófilas, Salmonella $s p$. bolores e leveduras, de acordo com a metodologia apresentada por Souza, Figueiredo e Santana (2015), os resultados obtidos foram comparados com a legislação que estabelece os Padrões Microbiológicos em Alimentos (BRASIL, 2001).

\section{Processamento dos brownies de inhame}

Foram realizadas cinco formulações de brownie de chocolate, com substituição parcial e total da farinha de trigo pela farinha de inhame. Os ingredientes utilizados no processamento estão descritos na Tabela 1.

Tabela 1: Formulações dos brownies

\begin{tabular}{cccccc}
\hline Ingredientes & F1 & F2 & F3 & F4 & F5 \\
Controle & $25 \%$ & $50 \%$ & $75 \%$ & $100 \%$ \\
\hline Farinha de trigo & $100 \mathrm{~g}$ & $75 \mathrm{~g}$ & $50 \mathrm{~g}$ & $25 \mathrm{~g}$ & $\ldots$ \\
Farinha de inhame & $\ldots$ & $25 \mathrm{~g}$ & $50 \mathrm{~g}$ & $75 \mathrm{~g}$ & $100 \mathrm{~g}$ \\
$\begin{array}{c}\text { Chocolate em barra (75\% cacau), Chocolate em pó } \\
\text { (100\% cacau) e açúcar cristal } \\
\text { Ovos }\end{array}$ & $100 \mathrm{~g}$ & $100 \mathrm{~g}$ & $100 \mathrm{~g}$ & $100 \mathrm{~g}$ & $100 \mathrm{~g}$ \\
& 3 & 3 & 3 & 3 & 3 \\
\hline
\end{tabular}

Fonte: Próprio autor

Os ingredientes para produção dos brownies foram pesados e fracionados em sacos plásticos. Em um recipiente foram adicionados o açúcar, a manteiga, previamente derretida, e os ovos, unindo-os até completa homogeneização. Posteriormente, no mesmo recipiente, adicionou-se a barra de chocolate derretida, a farinha e o cacau em pó.

Utilizou-se uma forma de alumínio quadrada, previamente untada e coberta com papel manteiga, para a acomodação da massa e cozimento em forno pré-aquecido a $180{ }^{\circ} \mathrm{C}$ por 25 
(vinte e cinco) minutos. Após o assamento da massa, os brownies foram cortados, com o auxílio de uma faca, em quadrados de 4x3cm (Figura 3).

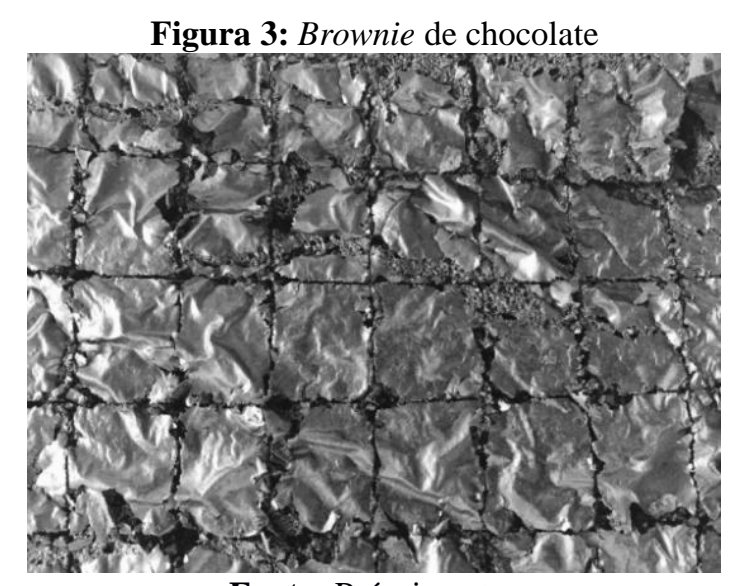

Fonte: Próprio autor

\section{Caracterização físico-química dos brownies}

Os brownies foram caracterizados, em triplicata, quanto aos parâmetros físico-químicos: $\mathrm{pH}$, acidez total titulável, sólidos solúveis totais, teor de água e sólidos totais conforme as Normas Analíticas do Instituto Adolfo Lutz (BRASIL, 2008).

\section{Análise de cor $L^{*}, a^{*}$ e b*}

As análises de cor $\left(\mathrm{L}^{*}, \mathrm{a}^{*} \mathrm{e} \mathrm{b}^{*}\right)$, foram realizadas nas amostras de brownie em espectrofotômetro portátil MiniScan HunterLab XE Plus, modelo 4500 L, equipado com iluminante D65, ângulo de observação de $10^{\circ}$ e calibrado com placa padrão branca $(X=80,5$; $Y=85,3 ; Z=90,0)$, obtendo-se os parâmetros $L^{*}, a^{*}$ e $b^{*}$, em que $L^{*}$ define a luminosidade ( $L^{*}$ $=0-$ preto e $\mathrm{L}^{*}=100-$ branco $)$ e $\mathrm{a}^{*}$ e $\mathrm{b}^{*}$ são responsáveis pela cromaticidade $\left(+\mathrm{a}^{*}\right.$ vermelho $\mathrm{e}-\mathrm{a}^{*}$ verde; $+\mathrm{b}^{*}$ amarelo e $-\mathrm{b}^{*}$ azul).

\section{Análise microbiológica dos brownies}

Os brownies foram submetidos a análises microbiológicas quanto aos parâmetros: Bacillus cereus, Salmonella sp., coliformes a $35^{\circ}$ e a $45^{\circ} \mathrm{C}$, seguindo a metodologia proposta por Silva et al. (2007) e comparados com o estipulado pela legislação (BRASIL, 2001).

\section{Análise sensorial}

O teste sensorial foi aplicado com 55 provadores não treinados, entre eles estudantes e servidores, do Instituto Federal de Alagoas - campus Murici. Foram definidos critérios de participação para a análise sensorial. O provador deveria ter entre 16 e 60 anos de idade, não 
poderia ter alergia ou intolerância aos ingredientes presentes na formulação do produto, preencher seus dados pessoais e assinar o termo de consentimento livre e esclarecido, e, por fim, tinham que ser consumidores de brownie.

A avaliação foi realizada por meio de uma escala hedônica que varia entre "1" a "9" para qualificar os atributos referentes à cor, aparência, odor e sabor, onde "1" refere-se à “desgostei muitíssimo" e "9" significa "gostei muitíssimo". Também foi analisado a intenção de compra, com a escala que varia de " 1 a 5 " onde " 1 " significa "certamente não compraria" e "5" significa "certamente compraria".

\section{Análise estatística}

Os dados experimentais das propriedades físico-químicas e dos testes sensoriais foram submetidos à comparação das médias e desvio padrão. Os resultados da análise estatística dos brownies com diferentes concentrações de farinha de inhame foram submetidos à análise de variância $(\mathrm{p}<0,05)$ ANOVA e ao teste de Tukey, para comparação entre as médias utilizando o Programa ASSISTAT versão 7.7 beta (SILVA; AZEVEDO, 2016).

\section{Resultados e Discussão}

Caracterização físico-química do inhame in natura

O inhame in natura apresentou teor e atividade de água elevado com 69,57\% e 0,98\%, respectivamente. Aquino et al. (2011) analisaram as características físico-químicas do inhame in natura e da farinha de inhame e obtiveram médias de 64,8\% para o teor de água e de $0,92 \%$ para a Aw do inhame in natura. Quanto aos sólidos totais, que é a diferença entre o peso da amostra e o conteúdo de umidade, foi obtido média de 30,4\%.

Na Tabela 2, encontram-se os valores médios e desvio padrão das características físicoquímicas do inhame in natura.

Tabela 2:Caracterização físico-química do inhame in natura

\begin{tabular}{cc}
\hline Parâmetros & Inhame in natura \\
\hline Teor de água (\%) & $69,6 \pm 0,15$ \\
Sólidos totais (\%) & $30,4 \pm 0,15$ \\
pH (potencial hidrogeniônico) & $6,3 \pm 0,3$ \\
Acidez total (\%) & $0,05 \pm 0,2$ \\
Aw (atividade de água) (\%) & $0,98 \pm 0,5$ \\
Sólidos solúveis totais & $0,2 \pm 0,15$ \\
\hline \multicolumn{2}{c}{ pH= potencial hidrogeniônico; Aw = atividade de água } \\
\multicolumn{2}{c}{ Fonte: Próprio autor }
\end{tabular}




\section{Elaboração e caracterização físico-química das farinhas em diferentes temperaturas} (Testes preliminares de secagem)

Com o objetivo de verificar a influência do teor de água na granulometria da farinha, foram realizados testes preliminares para determinação da melhor temperatura de secagem. Foi selecionada a farinha que apresentou menor teor de água e tempo de secagem, além da granulometria observada (Tabela 3 ).

Verifica-se que o teor de água diminuiu consideravelmente após a secagem, quando comparado com o inhame in natura, porém, a temperatura que obteve o melhor resultado com relação ao teor de água e desvio padrão foi a de $70^{\circ} \mathrm{C}$.

A secagem proporcionou um produto com baixo teor de água variando de 8,00\%, para o inhame desidratado a temperatura de $50^{\circ} \mathrm{C}$, a 3,12\%, para o inhame desidratado à $70^{\circ} \mathrm{C}$. Pode-se dizer que as três amostras desidratadas atendem aos padrões exigidos pela ANVISA (2005), a qual determina que o teor de umidade da farinha deve ser de, no máximo, $15 \%$. No trabalho desenvolvido por Miamoto (2008), ao analisar as características da farinha de inhame integral, obteve resultado de 5,37\% para umidade.

Tabela 3: Cinética de secagem

\begin{tabular}{cc}
\hline Amostras & Teor de água \\
\hline Inhame desidratado a $50^{\circ} \mathrm{C}$ & $8,45 \pm 1,6$ \\
Inhame desidratado a $60^{\circ} \mathrm{C}$ & $5,32 \pm 0,15$ \\
Inhame desidratado a $70^{\circ} \mathrm{C}$ & $3,12 \pm 0,13$
\end{tabular}

Fonte: Próprio autor

As farinhas, em diferentes temperaturas, foram caracterizadas quantos aos parâmetros físico-químicos: sólidos totais, sólidos solúveis totais, acidez total titulável e pH (Tabela 4).

Tabela 4: Caracterização físico-química da farinha de inhame em diferentes temperaturas

\begin{tabular}{cllllc}
\hline Amostras & Sólidos totais & Sólidos solúveis & Acidez Total & $\mathrm{pH}$ & SS/AT \\
\hline Farinha de inhame a $50^{\circ} \mathrm{C}$ & $91,55 \pm 1,6$ & $0,20 \pm 0,15$ & $0,15 \pm 0,01$ & $6,3 \pm 0,01$ & $1,33 \pm 0,01$ \\
Farinha de inhame a $60^{\circ} \mathrm{C}$ & $94,68 \pm 0,02$ & $0,19 \pm 0,01$ & $0,29 \pm 0,01$ & $6,3 \pm 0,03$ & $0,65 \pm 0,01$ \\
Farinha de inhame a $70^{\circ} \mathrm{C}$ & $96,88 \pm 0,1$ & $0,20 \pm 0,01$ & $0,56 \pm 0,01$ & $5,4 \pm 0,25$ & $0,36 \pm 0,01$ \\
\hline
\end{tabular}

Fonte: Próprio autor

Com base nos resultados que estão descritos na tabela 4, foi possível observar que o inhame desidratado na temperatura de $70^{\circ} \mathrm{C}$, amostra que apresentou o melhor resultado para o teor de água, obteve o maior valor para o parâmetro de teor de sólidos totais, caracterizado pela diferença entre o peso da amostra e o conteúdo de umidade, com média de 96,88\%. Para o teor 
de sólidos solúveis, não houve diferenças significativas entre as amostras. Os resultados para os parâmetros de acidez, pH e SS/AT (relação entre sólidos solúveis e acidez titulável) foram favoráveis para a amostra desidratada a $70^{\circ} \mathrm{C}$.

$\mathrm{O}$ pH do inhame é encontrado entre 5,5 e 6, caracterizando um tubérculo levemente ácido (UAILA, 2015). Sá et al. (2019) caracterizaram a farinha de inhame e obtiveram valores de 5,6 para o pH e Souza et al. (2012) encontraram valores de 5,5 para a farinha instantânea de fruta pão e acidez no valor abaixo de 3\%, que é o máximo permitido pela Portaria no 554 da Secretaria de Agricultura, do Abastecimento e Reforma Agrária (BRASIL, 1995). Os valores de $\mathrm{pH}$ encontrados nesta pesquisa, para a farinha desidratada à $70^{\circ} \mathrm{C}$, confere maior segurança contra o ataque microbiológico, visto que, a faixa de $\mathrm{pH}$ mais favorável para o crescimento microbiano é entre 6,5 a 7 (FERREIRA; ROBERTO; CAMISA, 2018).

\section{Análise microbiológica da farinha de inhame}

Foi selecionada a farinha que apresentou menor teor de água e melhor granulometria observada. Para a produção da farinha, foi desidratado $1 \mathrm{Kg}$ de inhame em estufa com circulação forçada de ar na temperatura de $70^{\circ} \mathrm{C}$ por $12 \mathrm{~h}$, sendo, posteriormente, caracterizada microbiologicamente e quanto aos parâmetros tecnológicos.

\begin{tabular}{cc} 
Tabela 5: Análise microbiológica da farinha de inhame \\
\hline Parâmetros & Farinha de inhame \\
\hline Coliformes a $35^{\circ} \mathrm{C}(\mathrm{NMP} / \mathrm{g})$ & $<3$ \\
Coliformes a $45^{\circ} \mathrm{C}(\mathrm{NMP} / \mathrm{g})$ & $<3$ \\
Bolores e Leveduras $(\mathrm{UFC} / \mathrm{g})$ & $<3$ \\
Bactérias Aeróbias Mesófilas $(\mathrm{UFC} / \mathrm{g})$ & Ausente \\
Salmonella (UFC/g) &
\end{tabular}

* $\mathrm{NMP} / \mathrm{g}=$ número mais provável por grama; $\mathrm{UFC}=$ unidades formadoras de colônias por grama.

Fonte: Próprio autor

A partir dos dados obtidos foi possível afirmar que a farinha de inhame desidratada a $70^{\circ} \mathrm{C}$ encontra-se dentro dos padrões exigidos pela RDC $\mathrm{n}^{\circ} 12$, de 02 de janeiro de 2001 (BRASIL, 2001).

\section{Análises tecnológicas}

Na Tabela 6, tem-se os valore médios das análises tecnológicas da farinha de inhame desidratada à $70^{\circ} \mathrm{C}$. 
Tabela 6: Análises tecnológicas da farinha de inhame

\begin{tabular}{lc}
\hline Parâmetros & Farinha de inhame a $70^{\circ} \mathrm{C}$ \\
\hline Densidade Aparente & $0,62 \mathrm{~g} / \mathrm{cm}^{3}$ \\
Densidade compactada & $3,14 \mathrm{~g} / \mathrm{cm}^{3}$ \\
Fator de Hausner & 0,20 \\
Índice de compressibilidade & $80,08 \%$ \\
\hline
\end{tabular}

Fonte: Próprio autor

De acordo com a Tabela 6, para o resultado de densidade aparente e densidade compactada, foi obtido a média de $0,62 \mathrm{~g} / \mathrm{cm}^{3}$ e $3,14 \mathrm{~g} / \mathrm{cm}^{3}$, respectivamente. Yashiki e Triboli (2018), estudando a farinha de inhame obtida por atomização, constataram valores de 0,46 $\mathrm{g} / \mathrm{cm}^{3}$ (densidade aparente) e $0,67 \mathrm{~g} / \mathrm{cm}^{3}$ (densidade compactada). Silva et al. (2013) relataram ao pesquisar a farinha de tapioca produzida no estado do Pará, obtiveram valores médio de 0,61 $\mathrm{g} / \mathrm{cm}^{3}$ para densidade aparente.

O Fator de Hausner (FH) apresentou valores médios de 0,20. Segundo Santhalakshmy et al. (2015) o fator de Hausner avalia a coesividade do material, e valores <1,2 são classificados como de baixa coesividade, FH entre 1,2 a 1,4 é de coesividade intermediária e FH >1,4 é considerado de alta coesividade.

O Índice de Carr expressa a capacidade de escoamento e compressão de um sólido (SOUZA, 2017). O índice de Carr (IC) apresentou valor de 80,08\% classificando a farinha com fluidez ruim ou muito ruim, o que a caracteriza como um pó coesivo. Ainda, de acordo com Santhalakshmy et al. (2015), valores de IC>45 são caracterizados como materiais cuja fluidez é muito ruim.

\section{Caracterização físico-química dos brownies de inhame}

Ao analisar os resultados da Tabela 7, observou-se que não houve um comportamento padrão, apresentando oscilações entre os tratamentos, embora não tenha havido diferença estatística entre o controle e as formulações com adição parcial de farinha de inhame. A formulação com $100 \%$ de farinha de inhame foi a que obteve o melhor resultado em relação ao teor de água.

Orsine, Martins e Lima (2016) elaboraram e caracterizaram brownie de chocolate obtido a partir de ingredientes dietéticos, light e não dietéticos e obtiveram os seguintes resultados: 22,68\% para teor de água; 77,32\% para sólidos totais; 6,29 para $\mathrm{pH} ; 41,10^{\circ}$ para sólidos solúveis totais. Souza e Roselino (2019) desenvolveram brownie de chocolate obtido a partir da 
biomassa de banana verde e farinha de arroz, e revelaram o resultado de $18,38 \%$ para o parâmetro de teor de água.

Tabela 7. Análises físico-químicas dos brownies de inhame

\begin{tabular}{|c|c|c|c|c|c|}
\hline \multirow[t]{2}{*}{ Parâmetros } & \multicolumn{5}{|c|}{ Brownies de chocolate com farinha de inhame } \\
\hline & Controle & $25 \%$ & $50 \%$ & $75 \%$ & $100 \%$ \\
\hline Teor de água $(\%)$ & $10,84^{\mathrm{a}} \pm 0,61$ & $11,29^{a} \pm 0,07$ & $10,50^{\mathrm{a}} \pm 0,05$ & $9,46^{\mathrm{a}} \pm 0,31$ & $6,21^{\mathrm{b}} \pm 0,7$ \\
\hline Sólidos totais $(\%)$ & $89,16^{\mathrm{a}} \pm 0,61$ & $88,71^{\mathrm{a}} \pm 0,07$ & $89,76^{\mathrm{a}} \pm 0,05$ & $90,54^{\mathrm{a}} \pm 0,31$ & $93,72^{\mathrm{b}} \pm 0,17$ \\
\hline $\mathrm{pH}$ & $7,61^{\mathrm{a}} \pm 0,03$ & $7,63^{\mathrm{a}} \pm 0,06$ & $7,47^{\mathrm{a}} \pm 0,09$ & $7,29^{\mathrm{a}} \pm 0,06$ & $7,28^{\mathrm{a}} \pm 0,01$ \\
\hline $\begin{array}{c}\text { Sólidos solúveis } \\
\text { totais }\left({ }^{\circ} \text { Brix }\right)\end{array}$ & $47,57^{\mathrm{b}} \pm 0,15$ & $52,84^{\mathrm{ab}} \pm 2,3$ & $56,92^{\mathrm{a}} \pm 2,6$ & $55,54^{\mathrm{a}} \pm 2,9$ & $58,60^{\mathrm{a}} \pm 0,45$ \\
\hline
\end{tabular}

Fonte: Próprio autor

\section{Análise de cor dos brownies}

A cor da superfície de um produto alimentício é de extrema importância pois está relacionada aos fatores de qualidade detectados pelos órgãos do sentido. A cor, depois do preço do produto, é o atributo mais importante na escolha de um alimento (GAVA; SILVA; FRIAS, 2008, p. 68).

A coordenada $\mathrm{L}^{*}$, referente a luminosidade, varia de 0 (preto) a 100 (branco). Quanto mais próximo de 0 , mais escura é a amostra e quanto mais próximo de 100, mais clara. Observase na Tabela 8 que todas as amostras obtiveram resultados de $L^{*}$ entre 10,03 e 15,79, assim caracterizando que as amostras possuem coloração escura, próprio de um produto elaborado com chocolate.

Padilha et al. (2009) estudaram o uso da farinha de yacon (Smallanthus sonchifolius) na elaboração de bolo de chocolate e avaliaram seu perfil sensorial e cromaticidade. As farinhas, em geral, apresentaram média de 37,85 para o parâmetro L* e foram consideradas escuras, já que apresentaram valores abaixo de $50\left(\mathrm{~L}^{*<50}\right)$.

Para as coordenadas $a^{*}$ e $b^{*}$ foram adquiridos valores positivos de $a+e b+$, respectivamente. Os resultados obtidos nesta análise demonstraram que todas as amostras tiveram coloração similar com valores de +a entre 2,04 a 2,71 e +b entre 1,07 a 1,88.

Tabela 8. Análise de cor dos brownies

\begin{tabular}{cccccc}
\hline Parâmetros & \multicolumn{4}{c}{ Brownie de chocolate com farinha de inhame } \\
\hline & $0 \%$ & $25 \%$ & $50 \%$ & $75 \%$ & $100 \%$ \\
\cline { 2 - 5 } Luminosidade $\left(\mathrm{L}^{*}\right)$ & 15,79 & 13,60 & 14,90 & 14,27 & 13,04 \\
Intensidade do vermelho $\left(+\mathrm{a}^{*}\right)$ & 2,71 & 2,04 & 2,47 & 2,60 & 2,23 \\
Intensidade do amarelo $\left(+\mathrm{b}^{*}\right)$ & 1,88 & 1,20 & 1,07 & 1,74 & 1,44 \\
\hline $\mathrm{L}^{*} 0=$ preto e $\mathrm{L}^{*} 100=$ branco; $+\mathrm{a}^{*}=$ vermelho $-\mathrm{a}^{*}=$ verde; $+\mathrm{b}^{*}=$ amarelo $-\mathrm{b}^{*}=\mathrm{azul}$ \\
Fonte: Próprio autor
\end{tabular}

Machado (2012) desenvolveu bolo de chocolate light a partir da farinha do mesocarpo 
do maracujá e hidrocolóides e obteve valores de $\mathrm{L}^{*}$ menor que 50. Para $\mathrm{a}^{*}$ e $\mathrm{b}^{*}$ foram adquiridos valores positivos, caracterizando amostras com coloração mais escura, provenientes de produtos elaborados com chocolate.

\section{Caracterização microbiológica dos brownies de inhame}

A Agência Nacional de Vigilância Sanitária (ANVISA) na Resolução nº 12, de 02 de janeiro de 2001 (BRASIL, 2001) estabelece os critérios microbiológicos para os alimentos. Observa-se na Tabela 9 os resultados das análises microbiológicas dos brownies.

Tabela 9: Análises microbiológicas dos brownies de inhame

\begin{tabular}{lccccc}
\hline \multicolumn{1}{c}{ Parâmetros } & \multicolumn{5}{c}{ Brownies elaborados com farinha de inhame } \\
\hline \multirow{2}{*}{$\begin{array}{c}\text { Bacillus cereus } \\
\text { Salmonella }\end{array}$} & $<\%$ & $25 \%$ & $50 \%$ & $75 \%$ & $100 \%$ \\
\cline { 2 - 6 } Coliformes a $35^{\circ} \mathrm{C}$ & $<3 \mathrm{NMP} / \mathrm{g}$ & $<3 \mathrm{NMP} / \mathrm{g}$ & $<3 \mathrm{NMP} / \mathrm{g}$ & $<3 \mathrm{NMP} / \mathrm{g}$ & $<3 \mathrm{NMP} / \mathrm{g}$ \\
Coliformes a $45^{\circ} \mathrm{C}$ & $<3 \mathrm{NMP} / \mathrm{g}$ & $<3 \mathrm{NMP} / \mathrm{g}$ & $<3 \mathrm{NMP} / \mathrm{g}$ & $<3 \mathrm{NMP} / \mathrm{g}$ & $<3 \mathrm{NMP} / \mathrm{g}$ \\
\hline
\end{tabular}

A análise de Bacillus Cereus é importante no caso de produtos que sofreram tratamento térmico ou aquecimento. Essa bactéria pode formar esporos resistentes, sobreviver a temperaturas elevadas, se multiplicar e provocar doenças de origem alimentar (GAVA; SILVA; FRIAS, 2008). De acordo com a legislação, no que se refere à Bacillus cereus, o máximo permitido é de $10^{3} \mathrm{UFC} / \mathrm{g}$. Nesta pesquisa foram encontrados valores de $<10 \mathrm{UFC} / \mathrm{g}$ em todas as formulações. Este resultado é semelhante ao trabalho desenvolvido por Orsine, Martins e Lima (2016) que avaliaram microbiologicamente as amostras de brownie de chocolate light e encontraram <10 UFC/g. No estudo feito por Machado et al. (2019) obtiveram valores $<10^{2}$ UFC/g para as amostras de bolo de chocolate, constatando que não houve contaminação microbiológica dos produtos.

A Salmonella é uma bactéria patogênica e tem como habitat o trato intestinal do homem e de animais e são importantes por causarem doenças, principalmente veiculas por alimentos (GAVA; SILVA; FRIAS, 2008). De acordo com a Resolução RDC nº12, de 02 de janeiro de 2001, produtos de confeitaria devem apresentar ausência de Salmonella sp. As amostras avaliadas nesta pesquisa estão dentro dos padrões estabelecidos pela legislação. Ainda, de acordo com Orsine, Martins e Lima (2016) as amostras de brownie avaliadas apresentaram ausência de Salmonella. Resultado semelhante foi obtido por Morais et al., (2017), avaliaram 
microbiologicamente amostras de bolo de abóbora com chocolate e demonstraram ausência da bactéria.

O índice de coliformes expressa as condições higiênicas, não sendo, entretanto, um bom indicativo de contaminação fecal. Os gêneros que pertencem ao grupo "coliformes" são: Escherichia, Enterobacter, Klebsiella e Citrobacter (GAVA; SILVA; FRIAS, 2008). A temperatura ideal de desenvolvimento é à $35^{\circ} \mathrm{C}$. A Resolução ${ }^{\circ} 12$ da ANVISA estabelece como padrão para produtos de confeitaria o máximo de $10^{2} \mathrm{UFC} / \mathrm{g}$ de coliformes. Nesta pesquisa, como demonstrado na Tabela 9, foram encontrados valores $<3 \mathrm{NMP} / \mathrm{g}$.

Quanto aos coliformes à $45^{\circ} \mathrm{C}$, corresponde praticamente à contagem de Escherichia coli e é utilizado como indicador da contaminação fecal. Este grupo, por estar adaptado à temperatura intestinal, é capaz de se desenvolver até $45^{\circ} \mathrm{C}$ (GAVA; SILVA; FRIAS, 2008). A legislação estabelece como padrão microbiológico o máximo de $10^{2} \mathrm{UFC} / \mathrm{g}$ de coliformes à $45^{\circ} \mathrm{C}$. Nesta pesquisa foram encontrados valores de $<3 \mathrm{NMP} / \mathrm{g}$ para todas as amostras de brownie, dessa forma, pode-se afirmar que o produto atende aos padrões microbiológicos.

\section{Análise sensorial dos brownies}

Os resultados da análise sensorial dos brownies de chocolate elaborados com $0 \%, 25 \%$, $50 \%, 75 \%$ e $100 \%$ de farinha de inhame, estão descritos no Gráfico 1.

Gráfico 1: Resultado da análise sensorial para os parâmetros de aparência, cor, odor e sabor.

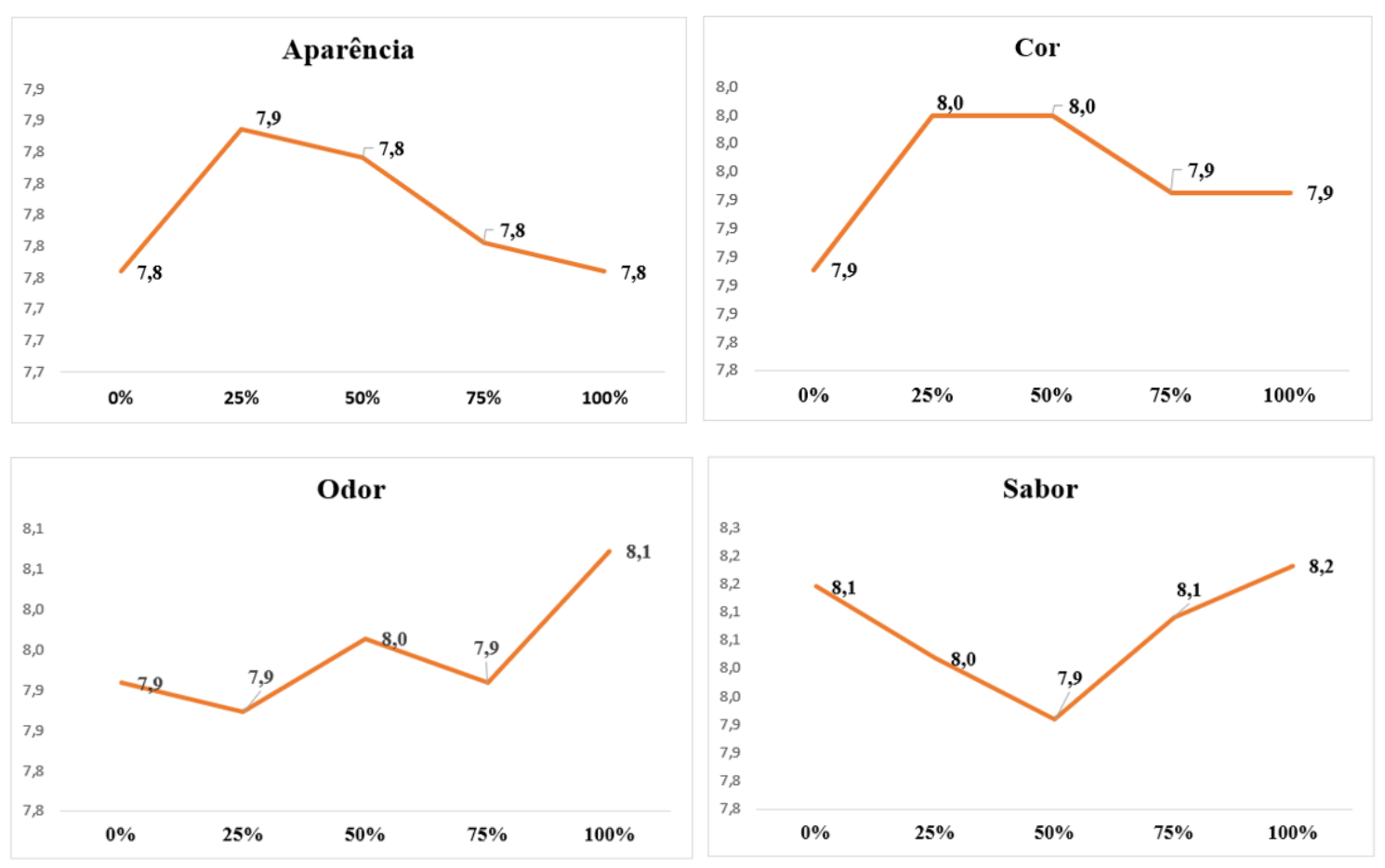

Fonte: Próprio autor 
Observa-se que as notas médias para os atributos do brownie elaborado (aparência, cor, odor e sabor) variaram entre 7,8 a 8,2, cujos termos hedônicos estiveram entre "gostei moderadamente/gostei muito" e "gostei muitíssimo".

De acordo com Gava, Silva e Frias (2008) o atributo "aparência" de um alimento incluem a cor, tamanho, forma, integridade, consistência e defeito de um produto alimentício. Os brownies elaborados com $0 \%$ a $100 \%$ de farinha de inhame obtiveram termos hedônicos entre "gostei moderadamente" e "gostei muito". O brownie elaborado com 100\% de farinha de inhame obteve a mesma média do brownie tradicional (0\%). Pode-se afirmar que no atributo "aparência", o brownie com $100 \%$ de farinha de inhame obteve as mesmas propriedades de qualidade do brownie tradicional. Resultado semelhante foi visto no trabalho feito por Morais et al. (2017), elaboraram um bolo de abóbora com chocolate utilizando $100 \%$ de farinha de arroz e obtiveram valor médio de 8,0 .

De acordo com Cobucci (2010) a característica “cor" é de extrema importância para a escolha de um produto alimentício, pois o primeiro contato do consumidor com o produto é visual. Observa-se que para o parâmetro "cor" foram obtidos valores médios de 7,9 a 8,0. Mais uma vez, o brownie elaborado com $100 \%$ de farinha de inhame obteve média semelhante ao brownie tradicional. Matos et al. (2017) analisaram sensorialmente brownie de chocolate elaborado com farinha de banana verde e demonstraram valores médios de 7,58 e 7,85 para os brownies produzidos com $100 \%$ de farinha de trigo e $100 \%$ de farinha de banana verde, respectivamente.

Odor e sabor são dois fatores de qualidade importantes na escolha de um produto alimentício. De acordo com Gava, Silva e Frias (2008) o sabor é uma resposta integrada às sensações do gosto e do aroma (saboroma) caracterizando o flavor. Para a característica "odor" e "sabor", foi alcançado média entre 7,9 a 8,1 e 7,9 a 8,2, respectivamente. Diferindo dos resultados encontrados nesta pesquisa, Silva et al. (2017) avaliaram sensorialmente brownie elaborado com farinha de berinjela e soro de leite caprino e revelaram valores médios de 5,79 e 6,02, para os atributos odor e sabor, respectivamente.

No que se refere aos resultados da intenção de compra, demonstrados no Gráfico 2, a média obtida foi entre 4 a 5 , cujos termos hedônicos estiveram entre "provavelmente compraria" e "certamente compraria". Entre as amostras de $0 \%$ a $75 \%$ os resultados foram semelhantes, com valores médios de 4,0. O produto que obteve mais escolhas quanto ao termo hedônico de "certamente compraria" foi o brownie produzido com 100\% de farinha de inhame. Ainda, de acordo com Silva et al. (2017) alcançaram média de 3,63 ficando na faixa de "talvez comprasse/ talvez não comprasse". Morais et al. (2017) revelaram média de 4,4 para o bolo de 
abóbora com chocolate a base de farinha de arroz.

Gráfico 2: Intenção de compra

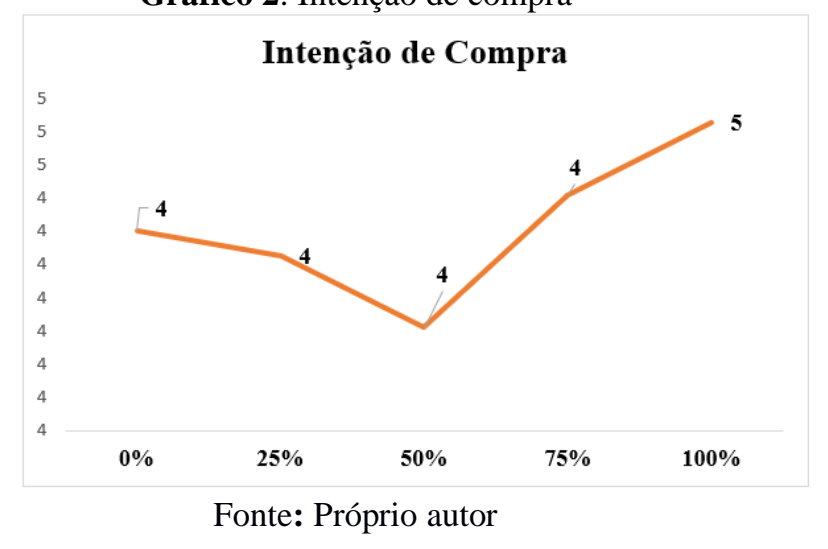

\section{Conclusões}

A utilização do inhame (Dioscorea sp.) para o processamento de farinha apresenta grande potencial para a indústria alimentícia e para os pequenos produtores rurais, tendo em vista, a facilidade de obtenção do tubérculo, características físico-químicas, microbiológicas, organolépticas, tecnológicas e sensoriais. A produção da farinha de inhame, em larga escala, além de contribuir para o crescimento do agronegócio, é uma alternativa viável para a fabricação de massas alimentícias isentas de glúten, destinadas aos indivíduos portadores da Doença Celíaca (DC). Ainda mais, o emprego da farinha de inhame para elaboração de subprodutos proporciona grande índice de aceitabilidade, maior vida de prateleira e evita o surgimento de problemas clínicos para os portadores da DC. Pode-se afirmar que, com base nos dados revelados nesta pesquisa, tanto a farinha de inhame quanto o brownie de chocolate apresentaram excelentes indicativos para o setor alimentício.

\section{Referências}

ANVISA. Agência Nacional de Vigilância Sanitária. Alimentos associados a alergias começam a ser rotulados com advertência ao consumidor. Junho, 2016.

ANVISA. Agência Nacional de Vigilância Sanitária. Resolução - RDC nº . 263, 22 de setembro de 2005. Regulamento técnico para produtos de cereais, amidos, farinhas e farelos.

AQUINO, A. C. M. S; SANTOS, J. C; SILVA G. F. Caracterização físico-química e microbiológica de farinha de inhame durante o armazenamento em diferentes embalagens. Scientia Plena, v.7, n.11, p.1-5, 2011. 
ARAUJO, H. M. C.; ARAUJO, W. M. C.; BOTELHO, R. B. A; ZANDONADI, R. P. Doença celíaca, hábitos e práticas alimentares e qualidade de vida. Rev. Nutr. [online]. 2010, vol.23, n.3, pp.467-474. ISSN 1415-5273. https://doi.org/10.1590/S1415-52732010000300014.

BRASIL. Normas analíticas do Instituto Adolfo Lutz: Métodos químicos e físicos para análises de alimentos. $4^{\text {a }}$ ed. Digital, São Paulo, 2008. 1020 p.

BRASIL. Agência Nacional de Vigilância Sanitária. Resolução - RDC nº 216, de 15 de setembro de 2004. Regulamento técnico de boas práticas para serviços de alimentação. Diário oficial de Brasília, Brasília, 16 de setembro de 2004.

BRASIL, Agência Nacional de Vigilância Sanitária. Resolução-RDC nº 12, de 02 de janeiro de 2001. Regulamento técnico sobre os padrões microbiológicos para alimentos. Diário Oficial de Brasília, Brasília, 02 de janeiro de 2001. Seção 1.

BRASIL. Portaria n. 554, de 30 de agosto de 1995. Norma de identidade, qualidade, apresentação, embalagem, armazenamento e transporte da farinha de mandioca. Diário Oficial da República Federativa do Brasil, Brasília, DF, 01 set. 1995.

BRITO, T. T.; SOARES, L. S.; FURTADO M. C.; CASTRO, A. A.; CARNELOSSI, M. A. G. Composição centesimal de inhame (Dioscorea sp.) in natura e minimamente processado. Scientia Plena, v.7, n.6, 2011.

COBUCCI, R. M. A. (2010). Análise Sensorial: Apostila do Curso. Curso Tecnológico Superior em Gastronomia. Pontifica Universidade Católica de Goiás

CONAB. Companhia Nacional de Abastecimento. A cultura do trigo. 2017. Disponível em: https://www.conab.gov.br/. Acesso em: 25 maio 2020.

CHEN, X.; LI, X.; HUANG, H.; WANG, T.; QU, Z.; MIAO, J.; Gao, W. (2017). Effects of drying processes on starch-related physicochemical properties, bioactive components and antioxidant properties of yam flours. Food Chemistry. p. 224-232.

FERREIRA, P.M.; ROBERTO, B.S.; CAMISA, J. Caracterização e aceitabilidade de barras de 
cereais enriquecidas com colágeno hidrolisado. Revista Virtual de Química, Arapongas, PR, v.10, n.1, p.155-171, mar.2018.

GAVA, A. J.; SILVA, C. A. B.; FRIAS, J. R. G. Aceitabilidade e fatores de qualidade dos alimentos. In: TECNOLOGIA de alimentos princípios e aplicações: princípios e aplicações. São Paulo: Nobel, 2008. cap. 1, p. 68-69. ISBN 978-85-213-1382-3.

GOULA, A. M.; ADAMOPOULOS, K. G. Spray drying of tomato pulp: effect of feed concentration. Drying Technology, New York, v.22, n.10, p.2309-2330, 2004.

LEÃO, F.; CLEMENTINO, G.; BARROS, I. Hortigranjeiros no Estado de Alagoas: Uma análise evolutiva da comercialização dentro do IDERAL/CEASA. Sebrae Alagoas, 2017. p. 173.

MACHADO, N.; MARQUES, R. M. P.; SILVA, S. Z.; BERNARDI, M. D. Pesquisa de consumo sobre produtos de panificação e desenvolvimento, caracterização físico-química e análise sensorial de bolo funcional de chocolate. Fag Journal of Health, [s. l.], ano 2019, v. 1, ed. 1, p. 10-23, 2019.

\section{MACHADO, M. M. Desenvolvimento de formulações de bolos de chocolate light utilizando} farinha do mesocarpo do maracujá e hidrocolóides. Orientador: Francine F. Padilha. 2012. 98 p. Dissertação (Mestrado) - Universidade Tiradentes, Aracaju, 2012.

MATOS, M.; BENINCÁ, S. C.; ZANLOURENSI, C. B.; SCHMITT, V. Análise sensorial e nutricional de brownie com farinha de banana verde. Revista brasileira de obesidade, nutrição e emagrecimento, São Paulo, 2017, v. 11, n. 69, p. 722-730. Disponível em: http://www.rbone.com.br/index.php/rbone/article/view/641. Acesso em: 15 jun. 2020.

MIAMOTO, J. B. M. Obtenção e Caracterização de Biscoito tipo Cookie Elaborado com Farinha de Inhame (Colocasia esculenta L). Orientadora: Joelma Pereira. 2008. 146 f. Dissertação (Mestrado) - Curso de Ciência dos Alimentos, Universidade Federal de Lavras, Minas Gerais, 2008.

MORAIS, J. S.; SASSI, K. K. B.; SOUZA, B. L.; MOREIRA, R. T.; MACIEL, J. F. Desenvolvimento e aceitação de bolo de abóbora com chocolate à base de farinha de 
arroz. Revista Brasileira de Agrotecnologia, Brasil, ano 2017, v. 7, ed. 2, p. 68-72.

NIELSEN, E. O que há na comida e na mente de brasileiro. 2016. Disponível em: https://www.nielsen.com/br/pt/insights/article/2017/o-que-ha-na-comida-e-na-mente-do brasileiro/. Acesso em: 23 maio 2020.

OLIVEIRA, J. M. S.; SOUSA, F. C.; SILVA, L. M. M.; MACHADO, N. A. F. Obtenção da farinha de inhame para processamento de brownie. In: 70 Reunião Anual da SBPC, 2018, Maceió - AL. Anais da 70ª Reunião Anual da Sociedade Brasileira para o Progresso da Ciência, 2018.

ORSINE, J. V. C.; MARTINS, L. F.; LIMA, K. K. B. Caracterização físico-química e microbiológica de brownie de chocolate utilizando-se ingredientes dietéticos, light e não dietéticos. Revista Brasileira de Tecnologia Agroindustrial, Ponta grossa, ano 2016, v. 10, ed. 2, p. 2053-2068.

PADILHA, V. M. et al. Perfil sensorial de bolos de chocolate formulados com farinha de yacon (Smallanthus sonchifolius). Ciênc. Tecnol. Aliment. [conectados]. 2010, vol.30, n.3, pp.735740. ISSN 0101-2061. https://doi.org/10.1590/S0101-20612010000300026 .

PESSOA, T. et al. Características físicas e físico-químicas de palitos de inhame submetidos à desidratação osmótica em solução salina. Holos, n.33, v. 7, 2017.

RODRIGUES, M. A.; FERREIRA, B. S.; SILVA, M. F.; COSTA, M. L. A.; ALMEIDA, A. S.; SANTOS, A. F. A bioquímica dos alimentos e doenças relacionadas. Diversitas Journal, [s.1.], v. 2, n. 2, p. 182-190, 8 ago. 2017. http://dx.doi.org/10.17648/diversitas-journal-v2i2.494.

SÁ, A. R. A. et al. Caracterização físico-química e nutricional de farinhas obtidas de inhame (Dioscorea spp.) e taro (Colocasia esculenta) comercializados em Petrolina-PE. Saúde (Santa Maria), [S.1.], jan. 2019. ISSN 2236-5834. 01 jun. 2020. doi:http://dx.doi.org/10.5902/2236583433647. 
SANTHALAKSHMY, S.; BOSCO, S. J. D.; FRANCIS, S.; SABEENA, M. Effect of inlet temperature on physicochemical properties of spray-dried jamun fruit juice powder. Powder Technology, v.274, n.1, p.37-43, 2015.

SIQUEIRA, M. V. B. M.; Nascimento, W. F.; Silva, L. R. G.; Ferreira, A. B.; Silva, E. F.; Ming, L. C.; Veasy, E. A. (2014) Distribution, management and diversity of yam local varieties in Brazil: a study on Dioscorea alata L. Braz. J. Biol., 74, 52-61.

SILVA, J. Y. P.; SILVA, A. R.; DOMINGOS, L. B. S.; MARTINS, A. C. S.; OLIVEIRA, M. E. G. Avaliação da aceitação sensorial de brownie elaborado com farinha de berinjela e soro de leite caprino. II Congresso brasileiro de ciências da saúde, Campina Grande, 2017, p. 1-9.

SILVA, P. A., et al. Caracterização de farinhas de tapioca produzidas no estado do Pará. Cienc. Rural, Santa Maria, v. 43, n. 1, p. 185-191, 2013.

SILVA, F. A. S.; AZEVEDO, C. A. V. (2016). The Assistat Software Version 7.7 and it use in the analysis of experimental data. Afr. J. Agric. Res. Vol. 11 (39), pp. 3733-3740, 29 September. DOI: 10.5897/AJAR2016.11522.

SILVA, T. S. G.; FURLANETTO, T. W. Diagnóstico de doença celíaca em adultos. Revista da Associação Médica Brasileira, Rio Grande do Sul, Porto Alegre, v. 1, n. 56, p. 122-126, 2010. Disponível em: https://www.scielo.br/pdf/ramb/v56n1/27.pdf. Acesso em: 23 maio 2020.

SILVA, N.; JUNQUEIRA, V. C. A.; SILVEIRA, N. F. A. Manual de métodos de análise microbiológica de alimentos. São Paulo: Varela, 2007. 295p.

SOUZA, M. F.; ROSELINO, M. N. Desenvolvimento, caracterização e aceitação de brownie de cacau potencialmente funcional. Rasbran, São Paulo, ano 2019, n. 2, ed. 10, p. 47-51, 2019. Disponível em: https://rasbran.emnuvens.com.br/rasbran/article/view/1466/263. Acesso em: 8 jun. 2020.

SOUSA, Francinalva Cordeiro de. Compostos bioativos e capacidade antioxidante de cajá e umbu-cajá obtidos por liofilização. Orientadores: Ana Paula Trindade Rocha e Josivanda 
Palmeira Gomes. 2017. 183 f. Tese (Doutorado) - Curso de Engenharia Agrícola, Universidade Federal de Campina Grande, Campina Grande, 2017.

SOUZA, J. R.; FIGUEIREDO, R. M.; SANTANA, C. M. P. Qualidade microbiológica da farinha de mandioca comercializada na região sudoeste da bahia. Revista Brasileira de Produtos Agroindustriais, Campina Grande, v. 2, n. 17, p.117-123, 2015.

SOUZA, D. S. et al. Elaboração de farinha instantânea a partir da polpa de fruta-pão (Artocarpus altilis). Cienc. Rural, Santa Maria, v. 42, n. 6, p.1124-1129, jun. 2012.

SOUZA, R. L. A.; OLIVEIRA, L. S. C.; SILVA, F. L. H.; AMORIM, B. C. Caracterização da poligalacturonase produzida por fermentação semi-sólida utilizando-se resíduo do maracujá como substrato. Revista Brasileira de Engenharia Agrícola e Ambiental, Campina Grande, v.14, n.9, p.987-992, 2010.

UAILA, E. D. Estudo fitoquímico e avaliação do valor nutricional do tubérculo inhame (dioscorea spp.). Orientadores: Amália Uamusse e Victor Sevastianov. 2015. 93f. dissertação (mestrado), Universidade Eduardo Mondlane, Maputo, 2015.

WALTER, M., SILVA, L. P. \& EMANUELLI, T. (2005) Amido resistente: características físico-químicas, propriedades fisiológicas e metodologias de quantificação. Ciência Rural, 35, 974-980.

YASHIKI, L. G.; TRIBOLI, E. P. R. Caracterização de farinha de inhame obtida por atomização. 2018. Disponível em: https://maua.br/files/122017/caracterizacao-farinha-inhameobtida-por-atomizacao-261721.pdf. Acesso em: 25 maio 2020.

YUSOF, Y. A.; SALLEH, F. S. M.; CHIN, N. L.; TALIB, R. A. The drying and tabletting of pitaya powder. Journal of Food Process Engineering, v.35, n.5, p.763-771, 2012. 